\title{
Microgravity-induced ocular changes in astronauts: a sight odyssey
}

\section{Alterações oculares causadas pela microgravidade em astronautas: uma odisseia visual}

\author{
Jayter Silva Paula ${ }^{1,2}$, Sanjay Girdhari Asrani ${ }^{2}$, Eduardo Melani Rocha ${ }^{1}$
}

\begin{abstract}
More than a new motivating force to the space race, the arrival of the American astronaut Scott Kelly from almost a year travel to the International Space Station promises a scientific milestone in the study of the long-term effects of the human body outside the Earth's atmosphere ${ }^{(1)}$. In addition to all the space-related data collected during the trip, the astronaut and his twin brother, Mark Kelly - nonparticipating to this mission, will be extensively compared. This study is analyzing laboratory samples from both, including assessments of the musculoskeletal, and immune system, genetic analysis and ocular evaluations, in order to increment knowledge related to microgravity effects on the human body. The results will be crucial for the Journey to Mars program (in 2030's) outlined in the bipartisan United State National Space Policy and National Aeronautics and Space Administration (NASA) Authorization Act issued in 2010.

Microgravity is defined as a very small gravity condition in which objects appear to be weightless ${ }^{(2)}$. Given the difficulties and cost of space travel, parabolic flight tests (producing transient periods of microgravity) and the head-down bed-rest studies (simulating the pressure effects of microgravity) has been used to examine several systemic and ocular changes ${ }^{(3)}$. In addition to space radiation-induced cataract, the effects of microgravity on the eyes are considered the most impactful health problems for the success of long-term space travels. Still, a minimal comparison can be obtained by the experiences on high-altitude climbing, which have also shown harmful consequences to the retina, optic nerve, and cornea (mainly related to corneal refractive surgeries) ${ }^{(3-5)}$. As an analogy to the importance of vision-threatening environmental scenarios, the book "Into thin air" authored by Jon Krakauer quotes high-altitude-related blurred vision resulting in a Mount Everest tragedy as the critical limitation to an adventurer(6)

The first ocular findings in space flights were related to the blurring of vision, described in the 60's and later were associated with the Visual Impairment and Intracranial Pressure (VIIP) syndrome ${ }^{(3,7)}$. The findings outlined in this syndrome could be explained by modifications in the fluid shift pattern resulting from altered pressures in several liquid compartments of the body, especially the intraocular pressure (IOP), the intracranial pressure (ICP) and the blood pressure. Thus, the neuroretinal-cerebrospinal fluid interface (including lamina cribrosa) could be affected by microgravity, due to the local "cul-de-sac" anatomy of the optic nerve head and the relative increased ICP transmitted to the eye by the subarachnoid space. As consequence, the optic nerve sheath distension, optic disc edema, vascular changes in the choroid and retina (eg., folds choroidal, thickening of the retinal fiber layer, cotton wool spots), "flattening" of the eyeball and a hyperopic shift have been described in several astronauts ${ }^{(3,8)}$. Still, a moderate acute IOP increase in the first moments in microgravity (probably due to congestion in the episcleral veins), followed by a steady IOP decrease were observed during longer periods under microgravity and in the post-flight evaluations $s^{(8,9)}$.

On the other hand, these ocular changes displayed in microgravity conditions, and potentially related to increased ICP, could not be directly compared with similar terrestrial disorders, such as idiopathic intracranial hypertension, because some astronauts participating in long-term space flights have not reported any visual symptoms or showed any change in their ocular examinations.

Hence, the understanding of the mechanisms responsible for the changes related to the VIIP syndrome is in the midst of a not completed scientific odyssey. Besides all the interests in comparing the results of the Kelly twins under different gravity, nutrition, and radiation conditions, their genetic similarities can bring new discernment to current poorly explained findings. In fact, a recent study showed that genetic background (1-carbon pathways polymorphism genes), combined with lower levels of B-vitamin (B6, folate, and riboflavin), and potentially the before-flight androgen status would be related to some VIIP-related ocular changes ${ }^{(10)}$. Despite the limitations, this study highlighted the involvement of individual factors not directly associated with the internal spacecraft environment in the development of ocular changes. But it is not just about the trip. Even with the use of spacesuits by the astronauts, Mars also presents 38\% of Earth's gravity, and several other vision threats related to its thin, and dusty atmosphere.
\end{abstract}

Submitted for publication: May 30, 2016

Accepted for publication: May 31, 2016

Department of Ophthalmology, Ribeirão Preto Medical School, University of São Paulo, Ribeirão Preto, Brazil.

2 Department of Ophthalmology, Duke University School of Medicine, Durham, NC, USA.
Funding: No specific financial support was available for this study

Disclosure of potential conflicts of interest: None of the authors have any potential conflict of interest to disclose.

Corresponding author: Jayter Silva Paula. Departamento de Oftalmologia, Otorrinolaringologia e Cirurgia de Cabeça e Pescoço. Faculdade de Medicina de Ribeirão Preto, USP. Av. Bandeirantes, 3.900 - Ribeirão Preto, SP - 14049-900 - Brazil - E-mail: jspaula@fmrp.usp.br 
Thus, aiming for a future two-years trip to Mars, there is much to do on Earth in the next two decades. Further astronauts selection processes may be even more complicated and competitive for interplanetary flights, but putting the universe in the foresight horizon of scientific search, new knowledge from the space may boost our modern terrestrial medicine.

\section{REFERENCES}

1. Kluger J. Scott Kelly Happy to Be Back on Earth: "This Feels Great." Time Magazine [Internet] 2016 March 2. [cited 2016 Jun 1]. Available from: http://time.com/4244421/ scott-kelly-year-in-space-land-soyuz/

2. DeFelice D. What is Microgravity? Natl Aeronaut Space Admin 2009 [2009 Feb 13; cited 2016 May 20]. Available from: http://www.nasa.gov/centers/glenn/shuttlestation/ station/microgex.html

3. Taibbi G, Cromwell RL, Kapoor KG, Godley BE Vizzeri G. The effect of microgravity on ocular structures and visual function: a review. Surv Ophthalmol. 2013;58(2):155-63.

4. Willmann G, Gekeler F, Schommer K, Bärtsch P. Update on high altitude cerebral edema including recent work on the eye. High Alt Med Biol. 2014:15(2):112-22.

5. Mader TH, White $\sqcup$. Refractive surgery safety at altitude. High Alt Med Biol. 2012; 13(1):9-12.

6. Krakauer J. Into thin air: a personal account of the Mount Everest disaster. New York: Villard Books; 1997
7. Duntley SQ, Austin RW, Taylor JH, Harris JL. Experiment S-8/D- 13, Visual Acuity and Astronaut Visibility. In: Gemini Midprogram Conference Including Experiment Results. Proceedings. Hampton VA: NASA; 1966

8. Mader TH, Gibson CR, Pass AF, Kramer LA, Lee AG, Fogarty J, et al. Optic disc edema, globe flattening, choroidal folds, and hyperopic shifts observed in astronauts afte long-duration space flight. Ophthalmology 2011;118(10):2058-69. Comment in: Ophthalmology. 2012;119(11):2420-1; author reply 2421-2.

9. Alexander DJ, Gibson CR, Hamilton DR, Lee SM, Mader TH, Otto C, et al. Evidence report. Risk of spaceflight-induced intracranial hypertension and vision alterations [Internet]. Houston, Texas: National Aeronautics and Space Administration; 2012. [cited 2016 May 30]. Available from: http://humanresearchroadmap.nasa.gov/evidence/ reports/viip.pd

10. Zwart SR, Gregory JF, Zeisel SH, Gibson CR, Mader TH, Kinchen JM, et al. Genotype, B-vitamin status, and androgens affect spaceflight-induced ophthalmic changes. FASEB J. 2016;30(1):141-8.

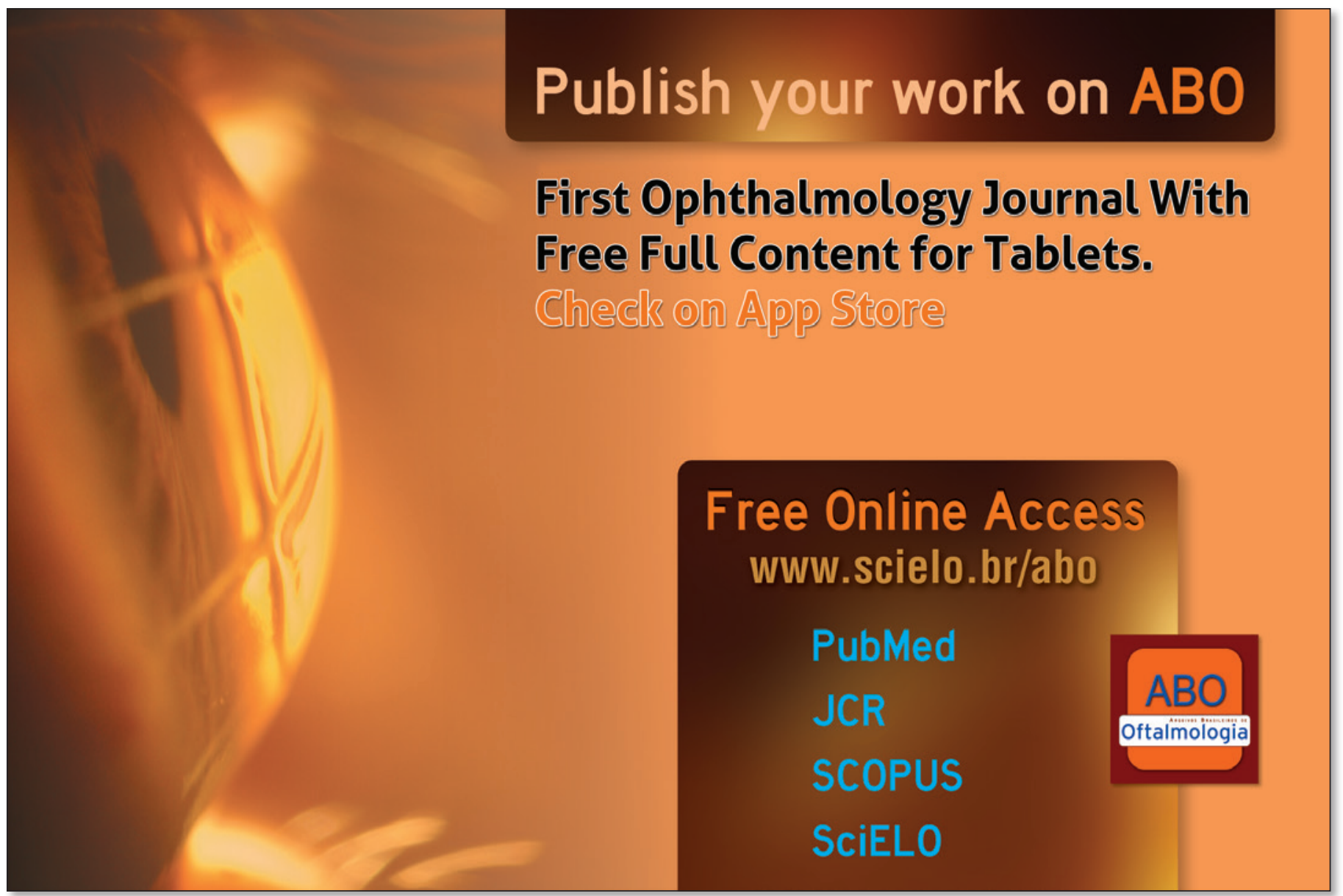

